\title{
The Total Quality Assurance Networking Model For Preventing Defects: Building An Effective Quality Assurance System Using A Total QA Network
}

Taku Kojima, Aoyama Gakuin University, Japan Kakuro Amasaka,' Aoyama Gakuin University, Japan

\begin{abstract}
The researchers construct a defect occurrence prevention technique called the Total QA Network Model that uses a combination of quality assurance tools and establishes partnerships. Their focus is on integrated quality assurance spanning different departments in manufacturing companies (from design to production) and extending further to part manufacturers. The Total Quality Assurance Networking Model is developed and its effectiveness is verified at a major corporation.
\end{abstract}

Keywords: quality assurance; defect prevention; partnerships; simultaneous achievement of QCD; Total QA Network; TQA-NM

\section{INTRODUCTION} development times, ensure high quality, and lower production costs.

There are many tools, such as quality function deployment (QFD) that can be used to ensure manufacturing quality, but they do not always produce sufficient results. There are three key technological components needed to take quality assurance to the next level: (1) the experience and skill of technical personnel, (2) the combined use of methods that take a scientific approach, such as failure mode and effect analysis (FMEA) and fault tree analysis (FTA), and (3) partnerships - both internal partnerships that extend from design through production and external partnerships built with suppliers.

The Total QA Network Model includes the above components and is introduced here as a new defect prevention technique. The Total Quality Assurance Model for preventing defects is then outlined and its effectiveness verified at a leading corporation.

\section{BACKGROUND}

\subsection{Manufacturing In Japan Today}

Product lifecycles are getting shorter as customers present more sophisticated and diverse needs. Japanese manufacturing needs to address these issues by shortening lead times throughout development, manufacturing, and sales.

However, recent large-scale recalls have raised social concerns and the number of incidents, as well as the number of vehicles recalled, is on the rise. These quality issues have naturally compromised user trust in addition to 
a loss in social standing for the companies themselves. Quality issues are not limited simply to manufacturing quality issues or manufacturing reliability - it has become increasingly important to treat them as corporate organizational issues as well.

\subsection{Necessity Of Preventing Defects}

In order to grasp actual quality assurance conditions, the researchers conducted 204 interviews and surveys at the quality assurance departments of ten manufacturing companies (assembly manufacturers and suppliers), which included some major corporations.

The investigation revealed that while many manufacturing companies are looking to shorten development times, they are also spending a great deal of their defect prevention efforts on preventing outflow rather than preventing occurrence itself. It was discovered that one reason for this is that developers believe that focusing on preventing outflow contributed more to shortening development times than focusing on occurrence prevention.

Occurrence prevention uses quality assurance tools like QFD or FMEA to predict what underlying factors are causing defects. But research indicated that these tools are currently not being sufficiently implemented. By putting effort into outflow prevention rather than occurrence prevention, fundamental solutions for reducing defects are never reached. Instead, it is critical that companies make the transition from quality assurance measures that prevent outflow to those that prevent occurrence, as shown in Figure 1.

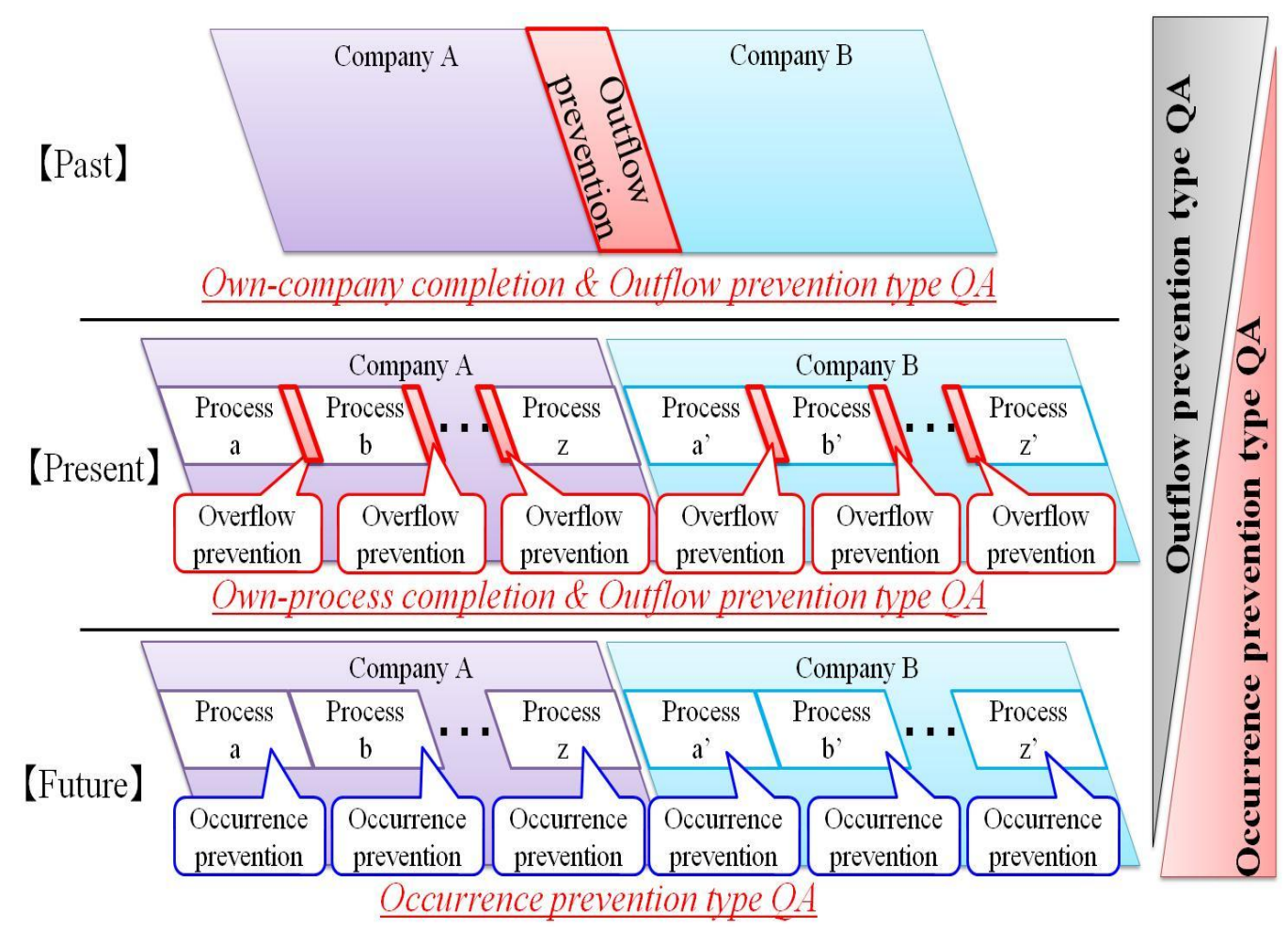

Figure 1: Quality Assurance Process Transitions

\section{ISSUES FACED BY QUALITY ASSURANCE DEPARTMENTS}

A statistical analysis (type III quantification method) was conducted on the data collected in section 2.2 "Necessity of preventing defects" to identify the issues faced by quality assurance departments, as shown in Figure 2. The figure indicates two levels of problems: those faced by managers (i) and those faced by staff members 
(workers) (ii). The three problems faced by managers (i) are: (1) development and deployment of quality assurance tools, (2) visualization of processes, and (3) transmission of know-how and expertise. These are the quality assurance issues from the perspective of management. The next three problems are those faced by staff members (ii). They are: (4) clear quality assurance standards, (5) quality of human resources, and (6) swift response to changing market conditions. These are the quality assurance issues from the perspective of the plant workers themselves.

As a result of the investigation and analysis, the researchers were able to clarify the critical components of achieving a high degree of quality assurance from the perspective of both managers and staff members (workers).

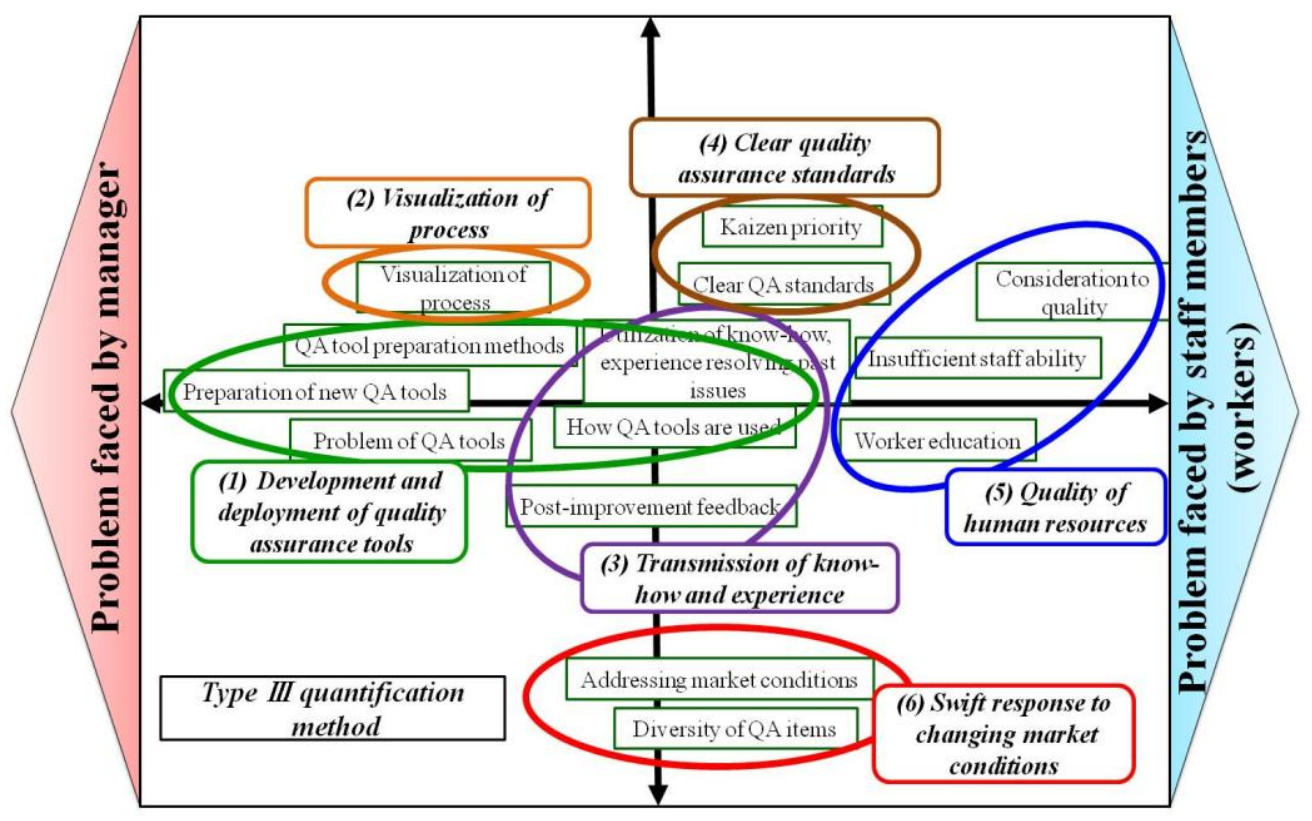

Figure 2: The Issues Faced by QA Departments

\section{CREATING THE TOTAL QA NETWORK MODEL}

\subsection{Creating The Total QA Network Model}

Putting effort into outflow prevention is necessary to fundamentally resolve defect issues. Effective partnerships - both internal partnerships that extend from design through production and external partnerships built with suppliers - are necessary to address quality issues as organizational issues within the company. In order to establish a total quality assurance system and strategically deploy it, the researchers came up with the Total QA Network Model, as shown in Figure 3. 


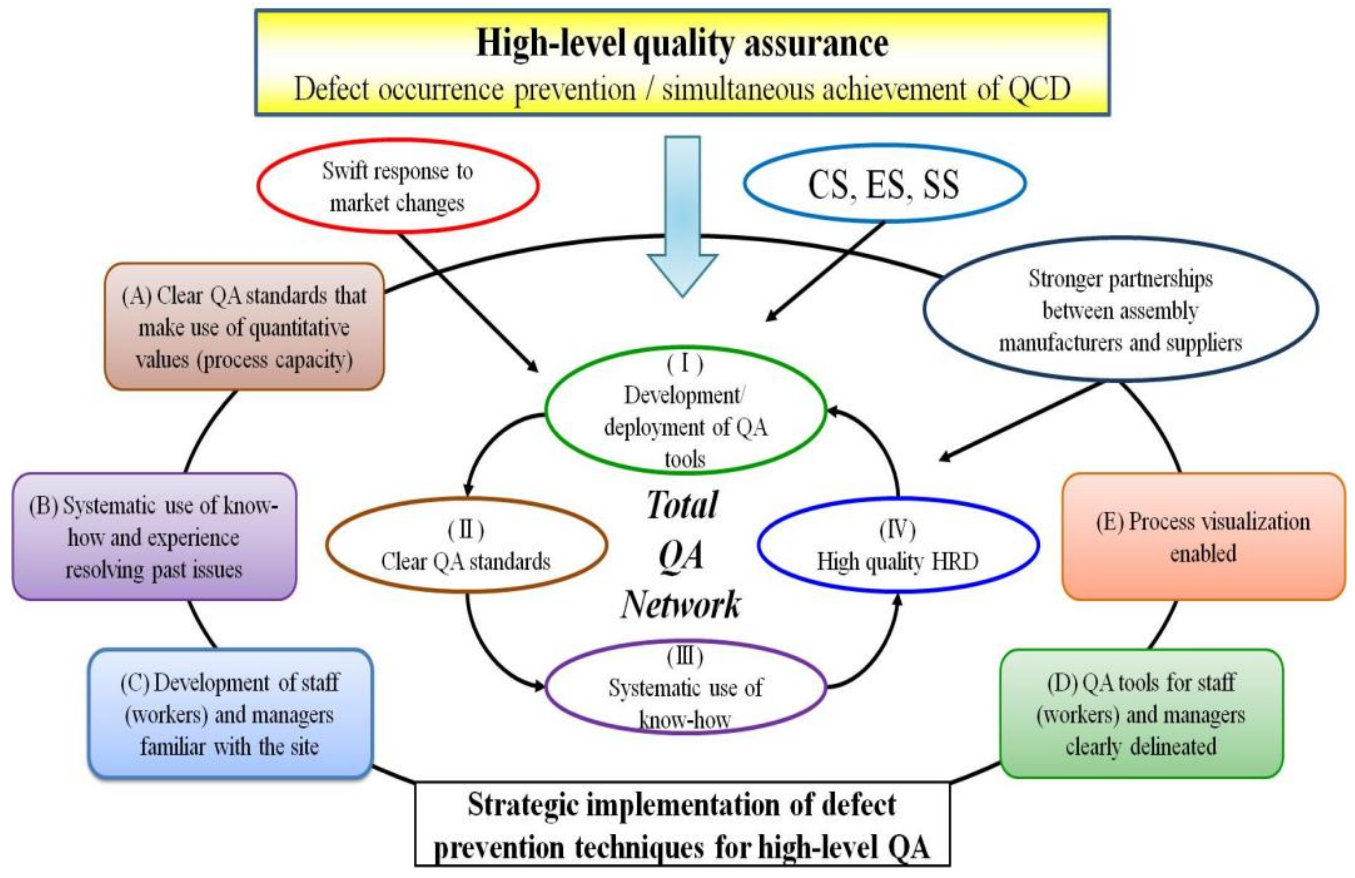

Figure 3: Total QA Network Model

The purpose of the model is to create a new quality assurance system that can be used to comprehensively carry out quality assurance. It is called the Total QA Network Model to indicate the cycling total quality assurance process for achieving defect prevention. The ultimate goal of the Total QA Network Model is to achieve customer satisfaction (CS), employee satisfaction (ES), and social satisfaction (SS) through high quality manufacturing. This is done through the prevention of defect occurrence and by supporting the simultaneous achievement of QCD that come from strategically deploying a high-level quality assurance process.

One of the technological components in achieving these goals is strengthening quality assurance networks by developing and deploying quality assurance tools. Another is establishing clear quantitative quality assurance standards (such as process capacity) that are not affected by worker experience. A third component is creating a system that can make use of worker expertise and information on past defects in an organized manner. A fourth component is the development of workers and frontline staff who are familiar with the site. The strategic implementation of these components will allow companies to prevent defect occurrence and simultaneously achieve quality, cost, and delivery (QCD).

\subsection{The Total QA Network Model Approach}

\subsubsection{Creating the Total QA Network Chart} Model.

The Total QA Network Chart, as shown in Figure 4, was created in order to deploy the Total QA Network

The chart is a defect occurrence prevention technique featuring a combination of quality assurance tools. It also uses FMEA and matrix diagrams to deploy partnerships.

The vertical axis of the chart identifies joint processes by suppliers and assembly manufacturers, from the arrival of goods to shipment. This creates a quality assurance "network" that eliminates gaps in quality assurance. The horizontal axis lists individual defects. The degree of quality assurance is indicated where the two axes intersect, which allows a quantitative value indicating the importance of process management tasks to be assigned to each. 


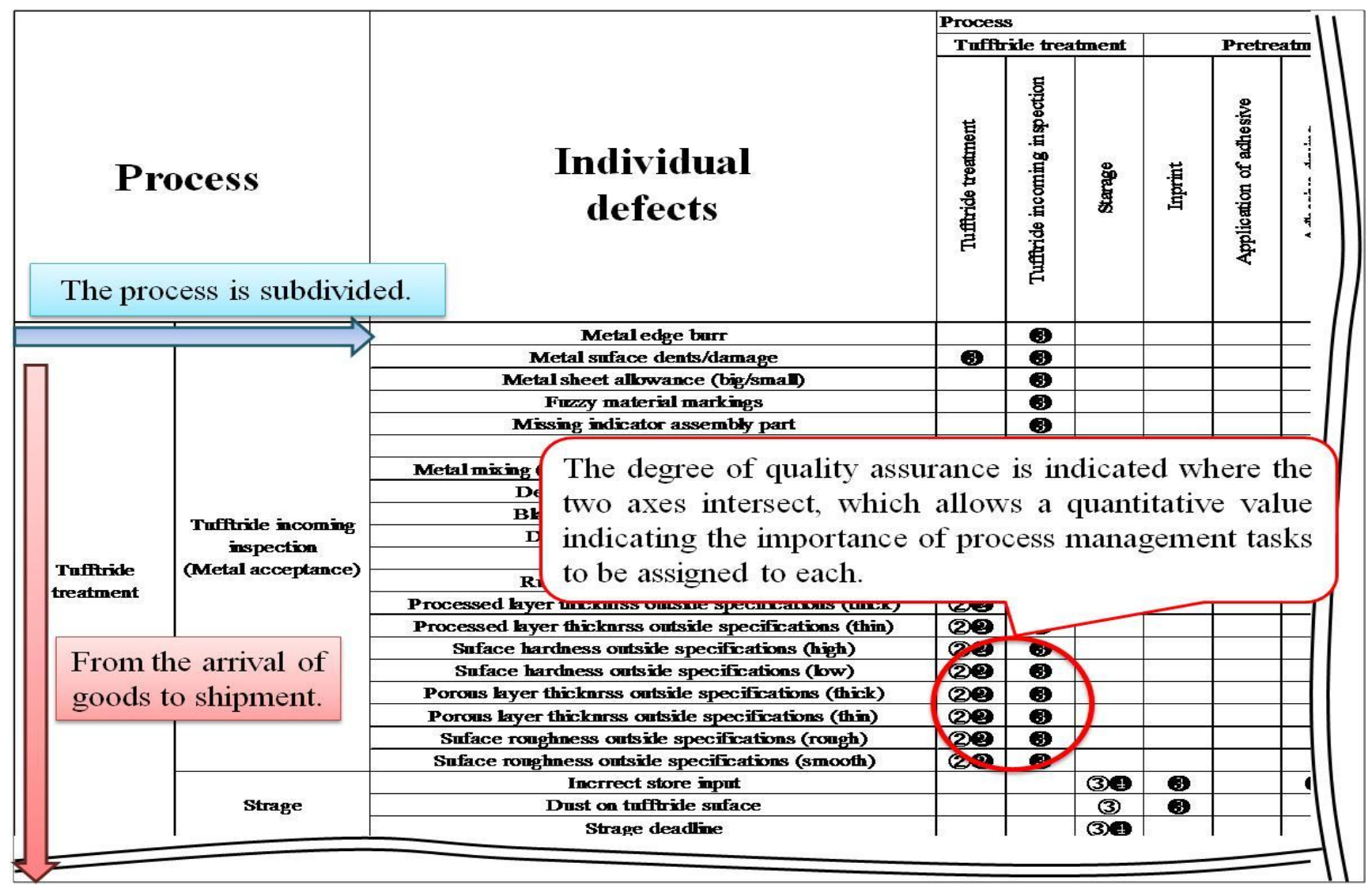

Figure 4: Total QA Network Chart

Each process is comprehensively evaluated on the basis of what the defect occurrence prevention tasks are for that process and how highly they are ranked in terms of the level of quality assurance.

\subsubsection{Ranking Occurrence And Outflow Prevention}

Table 1 assigns rankings to occurrence and outflow prevention. The importance of process management tasks is ensured based on the ranks shown for occurrence prevention and outflow prevention. This allows companies to carry out total quality assurance and establish a high-level quality assurance system.

Table 1. Occurrence And Outflow Prevention Rankings

\begin{tabular}{|c|c|c|c|}
\hline Level & Level I & Level 2 & Level 3 \\
\hline Assignment of QA Level & O, & Subjective 1-5 & $\begin{array}{c}\text { According to clear } \\
\text { standards 1-4 }\end{array}$ \\
\hline Development task & Full model change & Model change & Minnor change \\
\hline $\begin{array}{c}\text { Level of technology } \\
\text { at the company }\end{array}$ & Undeveloped & In transition & Advanced \\
\hline
\end{tabular}

\subsubsection{Level-Based Application}

Some participants in the investigation conducted section 2.2 "Necessity of preventing defects" felt that quality assurance tools did not match the scope or content of product development; they were not being used effectively, but simply being created as an empty exercise. Level-based application of the Total QA Network Chart, as shown in Figure 5, can resolve this issue, because it allows companies to deploy the chart in a way that matches the development of each product. 
Level-based application also allows quality assurance tools to be created in less time and contributes to the simultaneous achievement of QCD.

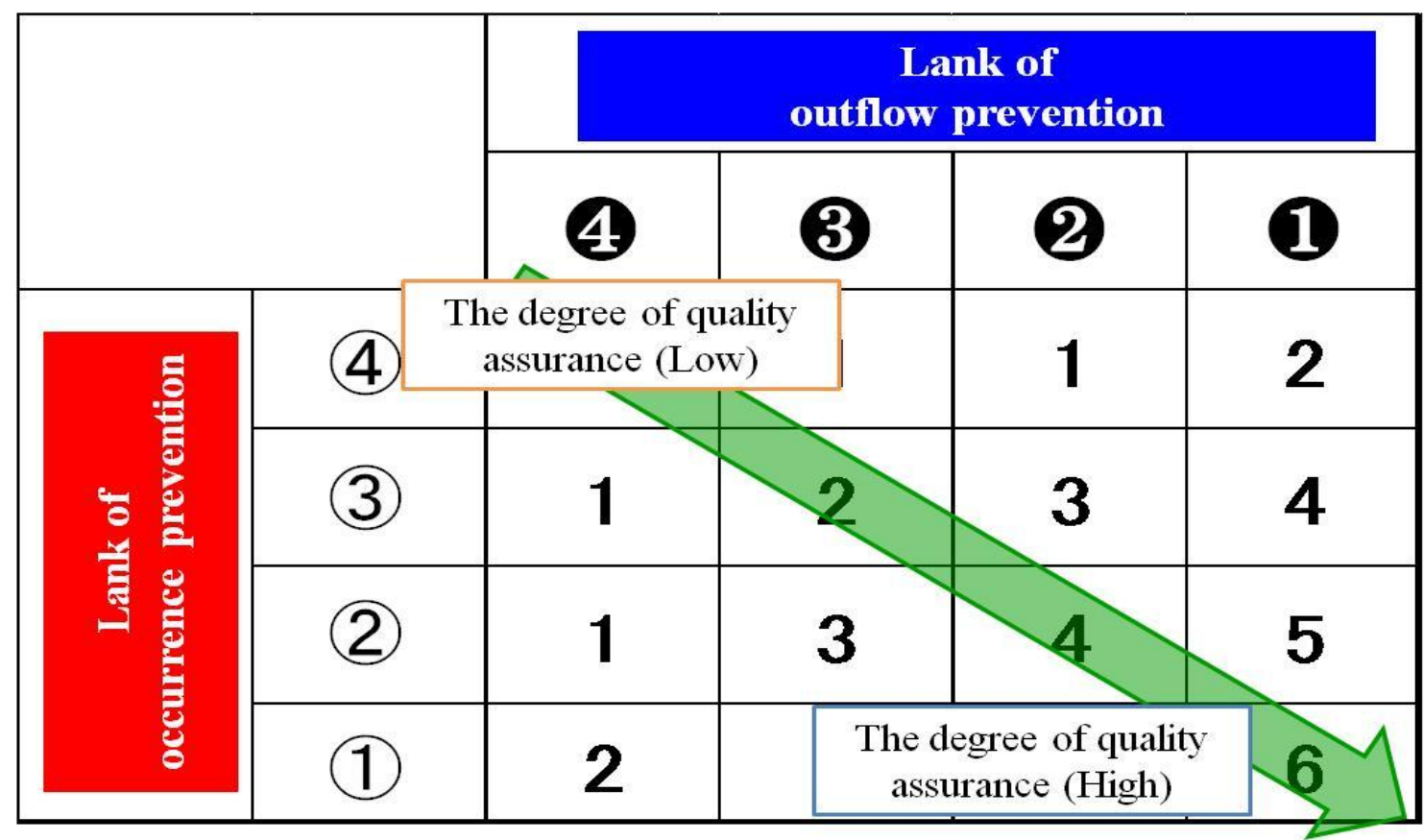

Figure 5: Level-Based Application Chart

\section{THE TOTAL QUALITY ASSURANCE NETWORKING MODEL FOR STRATEGIC DISTRIBUTION OF THE TOTAL QA NETWORK}

Japanese companies manufacture some of the highest quality products in the world, making successful defect occurrence prevention a top priority. The researchers constructed the Total Quality Assurance Networking Model (TQA-NM), as shown in Figure 6, as a way to systematize high-level quality assurance using the Total QA Network. This was done to address the importance of quality assurance through partnerships between assembly manufacturers and suppliers.

The ultimate goal of the TQA-NM model is to achieve high-level quality assurance through defect occurrence prevention as well as the simultaneous achievement of QCD. There are four essential guidelines that must be followed to achieve this goal. The first is quality assurance that makes use of the Total QA Network (A). The second is further improving partnerships between assembly manufacturers and suppliers by considering the way their respective quality assurance systems are set up (B). The third requirement is establishing a quality assurance database for the Total QA Network in order to share quality assurance information. The fourth requirement is making use of quality assurance tools in subsequent product development in order to pass on know-how and experience resolving past issues. 


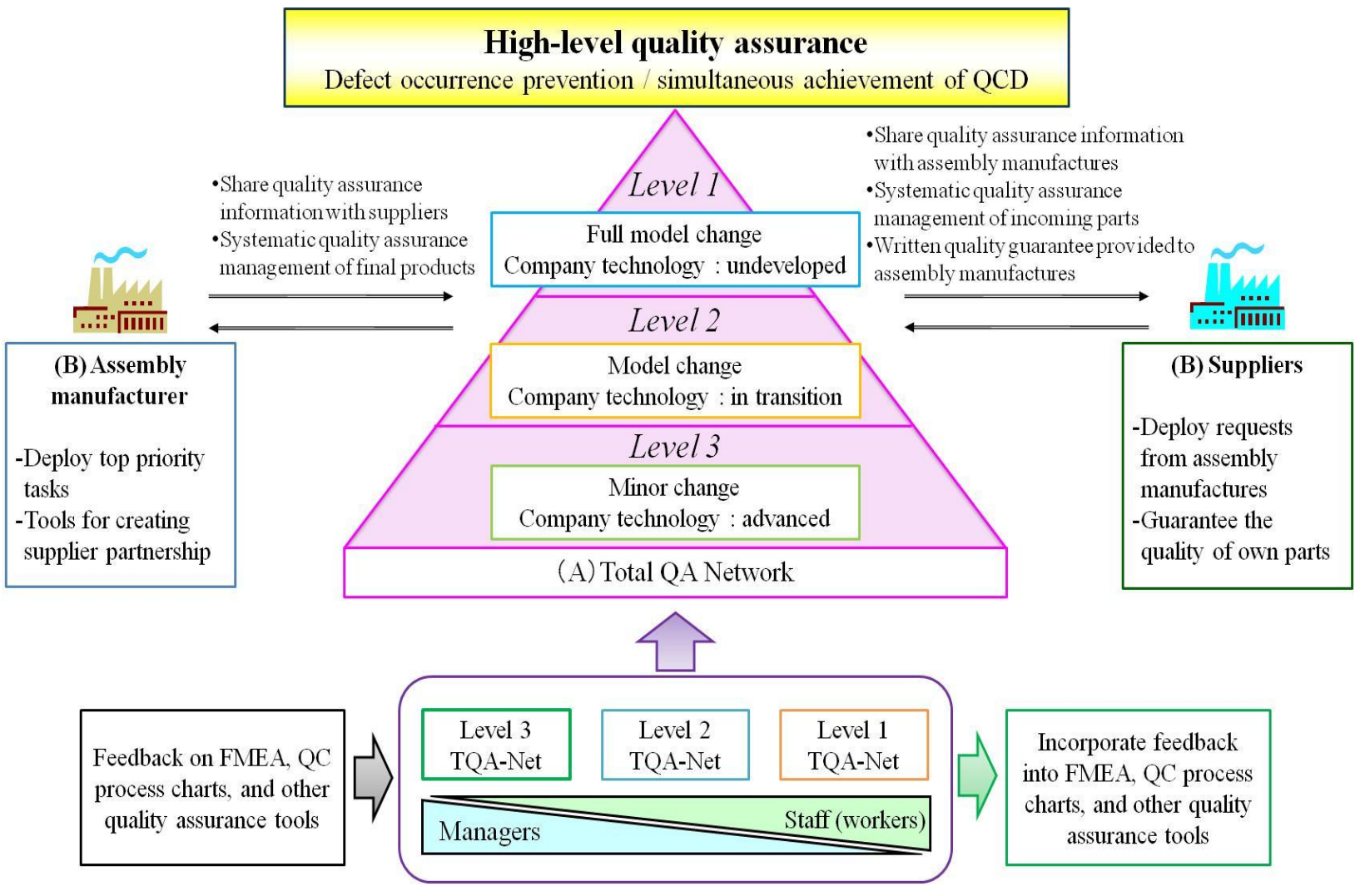

Figure 6: Total Quality Assurance Networking Model

\section{APPLICATION EXAMPLES}

The effectiveness of the HTQA-NM model was verified at a leading corporation. In this example, assembly manufacturer A (a leading automaker) and supplier B established a partnership (jointly developed activities) using the Total QA Network with the goal of improving the quality of brake pads to reduce noise. 
International Journal of Management \& Information Systems - Third Quarter 2011

Volume 15, Number 3

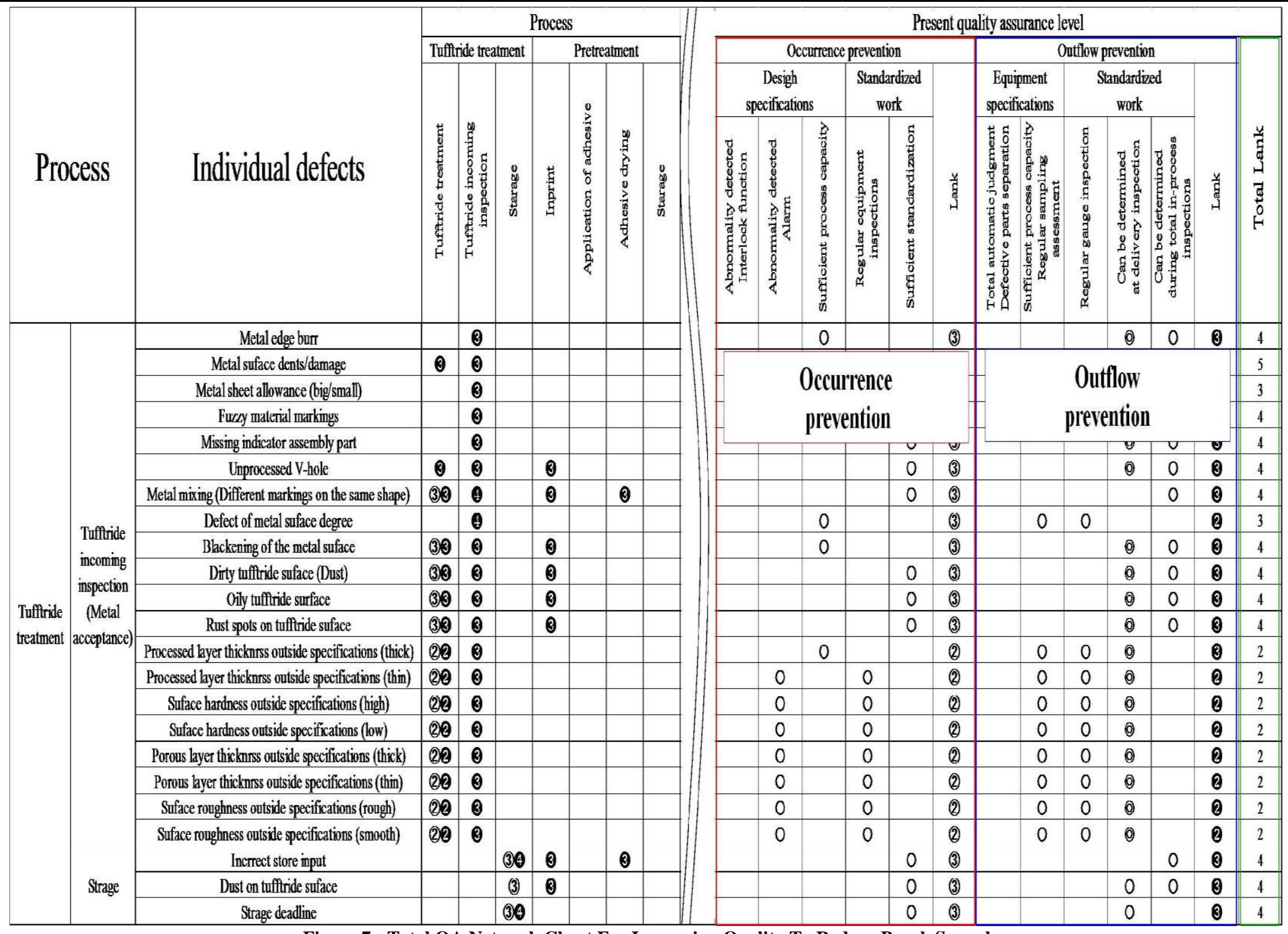

Figure 7: Total QA Network Chart For Improving Quality To Reduce Break Squeal 


\subsection{Technical Management}

Management activities took a technical approach to reducing the variations in quality that resulted in noise. The activities searched for a mechanism by conducting a variable factor analysis, which included consideration of quality evaluation techniques.

\subsection{Product Management}

A variable factor analysis was conducted on the brake pad products from a manufacturing perspective. The analysis sought to clarify the causal relationships leading to variations in process requirements and final products.

\subsection{Deploying The Total QA Network}

The researchers aimed to create more efficient business processes by taking full advantage of member expertise in technical management and in product management - and by carrying out these two activities side by side. If they are carried out completely in isolation from one another, it will be difficult for all participating members to have an awareness of shared goals. The two activities have therefore been deployed and linked using the Total QA Network, as shown in Figure 7.

\section{CONCLUSION}

This paper focuses on quality assurance activities that are integrated across different departments (from design through production) and extend to suppliers as well. The Total Quality Assurance Networking Model is constructed to establish partnerships and prevent defect occurrence, and its effectiveness is verified through application at a major corporation.

\section{AUTHOR INFORMATION}

Taku Kojima is a graduate student of the College of Science and Engineering at Aoyama Gakuin University.

Dr. Kakuro Amasaka is a Professor in the College of Science and Engineering at Aoyama Gakuin University, Japan. He received his Ph.D. degree in Precision Mechanical and System Engineering, Statistics and Quality Control at Hiroshima University in 1997. Since joining Toyota Motor Corporation in 1968, He worked as a quality control consultant for many divisions, and the General Manager of the TQM Promotion Division (1998-2000). His specialty is New JIT, Science TQM, Science SQC, Numerical Simulation (CAE) and Customer Science. Now, He has been serving as the vice chairman of JSPM (2003-2007) and JOMSA (2008-), the director of JSQC (2001-2003).

\section{REFERENCES}

1. K. Amasaka, New Japan Production Model, An advanced production management principle : Key to strategic implementation of New JIT, Business \& Economics Research Journal, Vol.6, No.7, 2007, pp.6779.

2. M. Yamaji and K. Amasaka, New Japan Quality Management Model : Implementation Of New JIT For Strategic Management Technology, International Business \& Economics Research Journal, Vol.7, No.3, 2008, pp.107-114.

3. K. Amasaka, Science SQC, New Quality Control Principle : The Quality Strategy of Toyota, Springer, 2004.

4. Ministry of Land, Infrastructure, Transport and Tourism, Recall trouble information on car, http://www.mlit.go.jp/jidosha/carinf/rcl/index.html. (in Japanese)

5. Ministry of Economy, Trade and Industry, Recovery of trust in manufacturing, Manufacturing base paper, 2009. (in Japanese)

6. K. Amasaka, S. Kurosu and M. Michiya, New Theory of Manufacturing-Surpassing JIT: Evolution of Justin-Time, Morikita Publisher, 2008. 
7. K. Amasaka, (editor), New Japan model- Science TQM: Theory and practice for strategic quality management, Study group of the ideal situation: the quality management of the manufacturing industry, Maruzen, 2007. (in Japanese)

8. K. Amasaka, Highly Reliable CAE Model: The Key To Strategic Development Of Advanced TDS, Journal of Advanced Manufacturing System, Vol.6, No.2, 2007, pp.159-176.

9. K. Amasaka et al., QA Network Activity Concerning Body Rust Prevention Utilizing SQC, The Japanese Society for Quality Control, The 59th Annual Technical Conference, 1995, pp.35-38. (in Japanese)

10. A. Takahashi, Quality Month Textbook - Meaning of TQM at Toyota-, Union of Japanese Scientists and Engineers, 1997. (in Japanese)

11. R. Mihara, M. Nakamura, M. Yamaji, K. Amasaka, Study on Business Process Navigation System "ABPNS”, International Journal of Management \& Systems, Vol.14, No.2, 2010, pp.51-58.

12. K. Amasaka, Partnering chains as the platform for Quality Management in Toyota, The 1st World Conference on Production and Operations Management, Sevilla, Spain, 2000, pp.1-13(CD-ROM).

13. K. Ebioka, M, Yamaji and K. Amasaka, A New Global Partnering Production Model "NGP-PM" utilizing “Advanced TPS", Journal of Business \& Economics Research, Vol.5, No.9, 2007, pp.1-8. 